\title{
Wind lidars reveal turbulence transport mechanism in the wake of a tree
}

\author{
Nikolas Angelou, Jakob Mann, and Ebba Dellwik \\ Wind Energy Department, Technical University of Denmark (DTU), Roskilde, 4000, Denmark \\ Correspondence: Nikolas Angelou (nang@dtu.dk)
}

Received: 14 July 2021 - Discussion started: 10 August 2021

Revised: 13 January 2022 - Accepted: 13 January 2022 - Published: 18 February 2022

\begin{abstract}
Solitary trees are natural land surface elements found in almost all climates, yet their influence on the surrounding airflow is poorly known. Here we use state-of-the-art, laser-based, remote sensing instruments to study the turbulent wind field in the near-wake region of a mature, open-grown oak tree. Our measurements provide for the first time a full picture of the mixing layer of high turbulence that surrounds the mean wind speed deficit. In this layer, we investigate the validity of a two-dimensional vectorial relation derived from the eddy-viscosity hypothesis, a hypothesis commonly used in modelling the turbulence transport of momentum and scalars in the atmosphere. We find that the momentum fluxes of the streamwise wind component can be adequately predicted by the transverse gradient of the mean flow. Using the mixing-length hypothesis we find that for this tree the corresponding turbulence length scale in the mixing layer can be approximated by one heightindependent value. Further, the laser-based scanning technology used here was able to accurately reveal threedimensional turbulent and spatially varying atmospheric flows over a large plane without seeding or intruding the atmospheric flow. This capability points to a new and more exact way of exploring the complex earth-atmosphere interactions.
\end{abstract}

\section{Introduction}

Solitary trees are common elements on earth's surface, planted or naturally grown, in urban and rural landscapes as well as in tundras and grasslands. Since trees are exceptionally efficient at extracting momentum from the wind (Lee et al., 2014; Dellwik et al., 2019), they can cause a significant effect in the near-surface atmosphere. This effect of the wind-tree interaction explains why trees are used as engineering elements in shelter belts to reduce the mean wind (Miller et al., 1974), decrease traffic noise (Kragh, 1981), improve crop productivity (Campi et al., 2009) and mitigate surface erosion (Miri et al., 2017). Because trees strongly reduce the wind speed, they also cause a downstream increase in the wind gradients. This, in turn, contributes to generation of turbulence, and thereby trees have a strong effect on the downstream turbulent transport of scalars (temperature, humidity, gases and particles) and momentum. An accurate description of the wind-tree interaction is also important for our understanding of the biological effect that wind has on trees, which determines their growth (Telewski, 1995) and influences their physiological response (de Langre, 2008) and their ability to reduce particulate air pollution (Chen et al., 2017). Yet, despite its fundamental importance, the scientific description of trees' interaction with the atmosphere is surrounded by large uncertainties.

Trees consist of multi-scale flexible elements, branches and leaves that respond dynamically to the wind (Gosselin, 2019). Due to these characteristics, it is difficult to evaluate whether simplified representations of trees scaled both in wind tunnels (Bai et al., 2012) and in numerical experiments (Gross, 1987; Gromke and Ruck, 2008) realistically reproduce the effects of natural trees. However, also atmospheric outdoor experiments on how trees influence the wind field have been limited by our inability to accurately observe the spatial variability in the wind field. By use of conventional in situ wind observations, the retrieved data represent the flow properties at one point, which is insufficient for the complete characterization of a complex flow where a highgradient wind field can occur. 
Over the last decade a new possibility of studying atmospheric flows has emerged based on the synchronous operation of three scanning Doppler wind light detection and ranging (lidar) instruments to simultaneously probe an air volume (Mikkelsen et al., 2017). Their design enables the measurement of the three-dimensional wind vector while rapidly scanning air volumes up to a distance of approximately $150 \mathrm{~m}$ (Sjöholm et al., 2018). This remote sensing technique does not require release of tracer particles, which is necessary when characterizing complex flows in wind tunnels. Instead, the technique is based on the detection of the Doppler shift in the backscattered laser light by naturally occurring aerosols (Henderson et al., 2005). This measurement methodology is especially useful in monitoring complex flow patterns, as in the case of wind over forests or hills (Mann et al., 2017) or in the case of wakes from wind turbines or surface obstacles, such as trees, since the whole flow field can be scanned. Here, we demonstrate a new application of this measurement technique, where the turbulent transport in the wake of a single tree is made visible and quantified. By this extension, it is possible to retrieve spatially distributed statistics of the wind in the real atmosphere that were previously only attainable in idealized numerical simulations or scaled wind tunnel studies. This direct measurement of the second-order moments enables the validation of the contested (Schmitt, 2007) and much-debated (Finnigan et al., 2015) eddy-viscosity hypothesis, which is a cornerstone in the simulation of weather (Powers et al., 2017), dispersion of pollution (Jeanjean et al., 2015), siting of wind turbines (Landberg et al., 2003) and atmosphere-canopy interaction (Cowan, 1968; Bache, 1986; Sogachev et al., 2012).

\section{Methodology}

\subsection{Experimental set-up}

The tree in focus in this study is an open-grown oak tree (Quercus robur), located $60 \mathrm{~m}$ from the shoreline of the Roskilde Fjord (Denmark) (32 U; 6175776 N, 694598 E) and $2.6 \mathrm{~m}$ above sea level (Fig. 1a-b). Its shape is common for solitary trees, and it has a height $H=6.5 \mathrm{~m}$ and width of $8.5 \mathrm{~m}$, which are within the typical range for open-grown oak trees (Hasenauer, 1997). The height of the tree is used to normalize all the spatial dimensions, which are denoted by the ${ }^{\wedge}$ symbol. The study of the wind field on the lee side of the tree is performed using measurements from a multi-lidar system denoted as short-range WindScanner. A short-range WindScanner system consists of three separate scanning wind lidar instruments, denoted in this document as $\mathrm{WS}_{1}, \mathrm{WS}_{2}$ and $\mathrm{WS}_{3}$, developed in the Wind Energy Department of the Technical University of Denmark (Mikkelsen et al., 2017). Each instrument is a mono-static, coherent, allfibre, infrared, continuous-wave (cw) wind lidar. The elevation and azimuth angles of the laser output are steered by an optical scanner head (Sjöholm et al., 2018). The scanner head consists of two individually rotating prisms that can direct the line of sight anywhere within a cone with a $120^{\circ}$ base angle. The backscatter light from the atmosphere for each line of sight is collected by a $3 \mathrm{in}$. telescope and detected using a homodyne configuration (Abari et al., 2014). For the needs of this study, we define a right-handed coordinate system whose origin is at the base of the tree's stem, and the $x$ axis is aligned to the predominant wind direction during the period of the experiment (positive $x$ axis pointing towards $110^{\circ}$ relative to the geographic north).

\subsubsection{Scanning mode}

The position of the three lidars, displayed in Fig. 2a, was selected based on the criteria that (i) the instruments should be as close as possible to a measuring position in order to ensure short probe lengths, (ii) the measuring area should be within the field of view of each lidar and (iii) the direction of the three lines of sight should at every scanning location enable the estimation of the three-dimensional wind vector. The latter is not fulfilled closest to the ground, where the line of sight of the laser beams is close to being horizontal, making it impossible to resolve the vertical component of the wind vector.

The lidars were programmed to acquire measurements within a vertical plane that was normal to the $x$ axis at a distance of $8.5 \mathrm{~m}(\hat{z}=1.3)$ from the tree towards the leeward direction. At that distance, the terrain is elevated by $0.25 \mathrm{~m}$ in comparison to the location of the tree. Due to the small difference in elevation and the relatively short distance between the tree and scanning plane, the geometry of the tree and the wind measurement locations are presented relative to the corresponding local ground level. The plane was synchronously scanned using a trajectory that consisted of 30 vertical lines that extended from $1.5 \mathrm{~m}(\hat{z}=0.2)$ to $16 \mathrm{~m}(\hat{z}=2.5)$. The lines spanned from -7.25 to $7.25 \mathrm{~m}(-1.1<\hat{y}<1.1)$ across the $y$ axis, forming a rectangle whose height and width were equal to $2.5 H$ and $2.2 H$, respectively. Due to the close distance from the tree and the dimension of the plane, the wake was always within the scanning area for the wind direction sector used in this study. The three laser beams were following the path of the vertical lines with an alternating direction of motion, starting from the lowest height (Fig. 2b). The scanning duration of each line was $710 \mathrm{~ms}$, which, including the transition time between two neighbouring lines (90 ms), resulted in a scanning duration of the whole rectangle of $24 \mathrm{~s}$. Following the completion of one scanning plane, the three laser beams were returning to the original location of the first measurement within $2 \mathrm{~s}$. Based on these features, approximately 25 iterations of the scanning pattern were performed per $10 \mathrm{~min}$ period. 

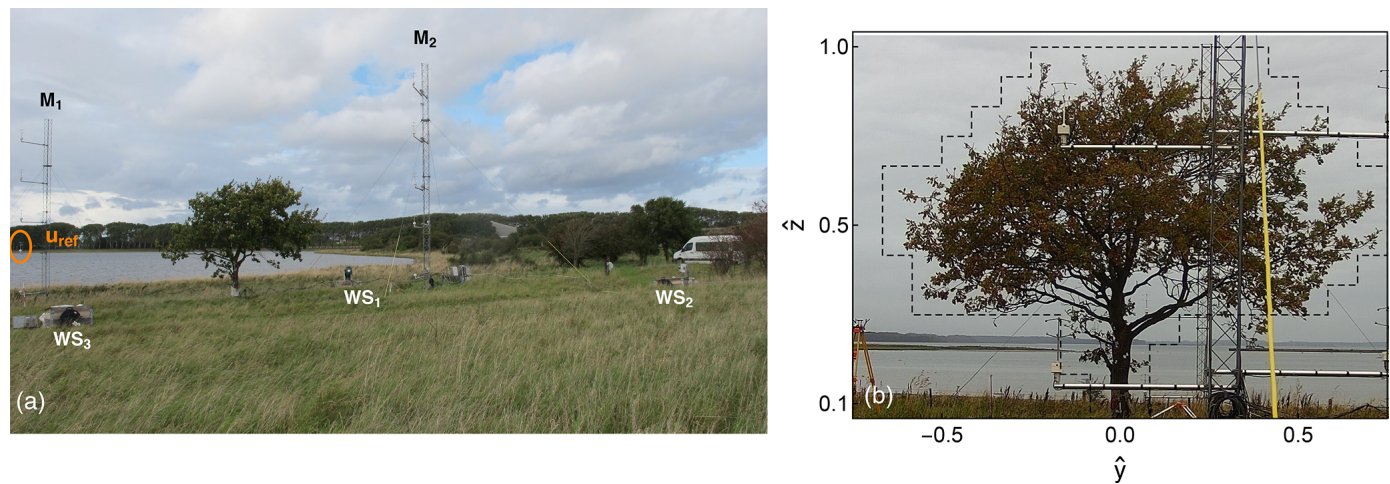

Figure 1. Photographs of experimental set-up. (a) Area surrounding the oak tree, where the three scanning wind lidars $\left(\mathrm{WS}_{1}\right.$, $\mathrm{WS}_{2}$ and $\left.\mathrm{WS}_{3}\right)$ and the two meteorological masts $\left(\mathrm{M}_{1}\right.$ and $\left.\mathrm{M}_{2}\right)$ were located. (b) A view from the lee side of the frontal area of the tree. The $y$ and $z$ axes are normalized by the tree height.
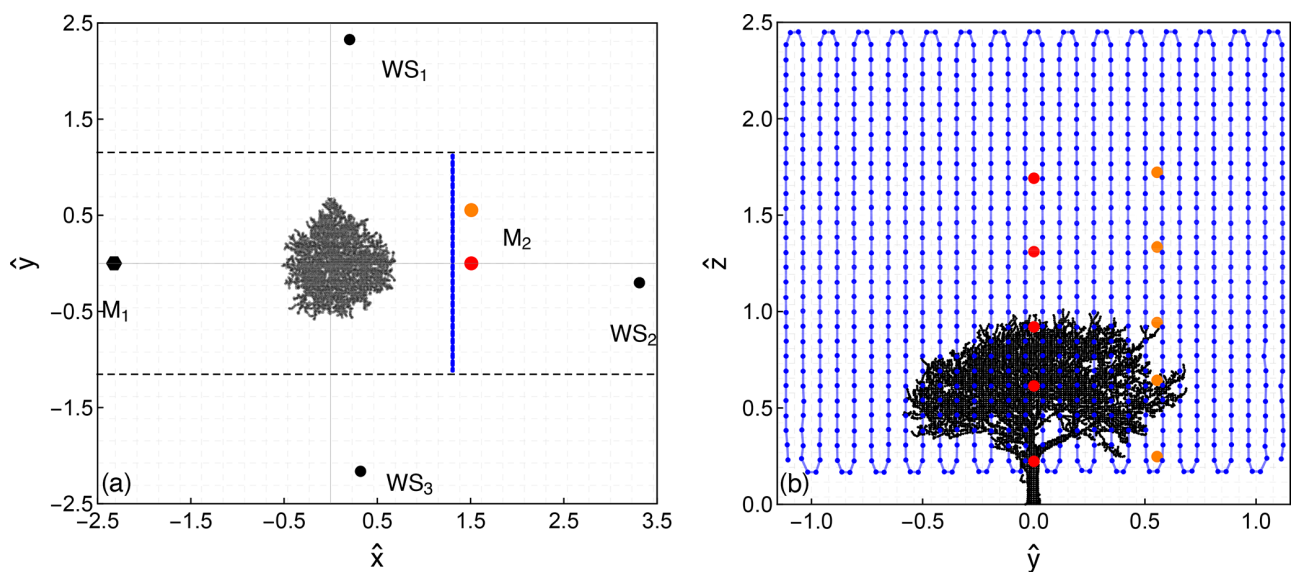

Figure 2. Experimental set-up. Drawings of the top (a) and the front (b) views of the experimental set-up, where the locations of the tree, the short-range WindScanners $\left(\mathrm{WS}_{1}, \mathrm{WS}_{2}\right.$ and $\mathrm{WS}_{3}$ ), the scanning pattern (blue), and the locations of the sonic anemometers on the upwind $\left(\mathrm{M}_{1}\right)$ and downwind $\left(\mathrm{M}_{2}\right)$ meteorological masts are depicted. The locations of the 10 sonic anemometers on the opposing booms on the $\mathrm{M}_{2}$ mast are indicated with red and orange colour, respectively.

\subsubsection{Grid}

The data acquired within an iteration of the scanning trajectory were grouped in square grid cells with a dimension of $0.5 \times 0.5 \mathrm{~m}$. The scanning speed $\left(20 \mathrm{~m} \mathrm{~s}^{-1}\right)$ and the sampling rate $(205 \mathrm{~Hz})$ of the instruments resulted in acquiring on average five Doppler spectra per grid cell per scanning pattern iteration. The Doppler spectra acquired in each grid cell were averaged in order to decrease the variance of the noise floor. Finally, the estimation of the Doppler frequency was performed using a method based on the median of the accumulated energy in the spectrum. This method has been proven to be less biased by noise (Angelou et al., 2012a) and to produce accurate first- and second-order statistics (Held and Mann, 2018).

In the cw wind lidars, as the ones used in this study, the probe length is dependent on the optical properties of the telescope (i.e. effective radius of the lens) and the focusing distance. The dimension of the probe length is based on the distribution of the intensity of the focused light along the line of sight, which is approximated by a Lorentzian function (Sonnenschein and Horrigan, 1971). Based on the configuration of the experimental set-up, the probe length of each lidar along the line of sight varied between 0.25 and $1.87 \mathrm{~m}$, depending on the measuring position. This range, in combination with the tilt and azimuth angles of each line of sight of the scanning wind lidar, results in a theoretical spatial resolution of $0.55-1.45 \mathrm{~m}, 0.49-0.89 \mathrm{~m}$ and $0.02-1.08 \mathrm{~m}$ for the $x$, $y$ and $z$ axis, respectively (Angelou, 2020). In the area close to the centre of the scanning plane $-0.7<\hat{y}<0.7$, where the wake is expected to be found, the spatial resolution varies between $0.55-0.96 \mathrm{~m}, 0.49-0.58 \mathrm{~m}$ and $0.02-0.34 \mathrm{~m}$ for the $x$, $y$ and $z$ axis, respectively. By assuming that the variation in the mean wind speed along the streamwise direction is negligible in those scales, the spatial resolution is comparable to the grid cell size $0.5 \mathrm{~m} \times 0.5 \mathrm{~m}$ used in this study. 


\subsubsection{Sonic anemometers}

In addition to the lidar measurements, in situ observations from multiple sonic anemometers were used as a reference of the upwind and downwind conditions in this study. Two meteorological masts were used, which were equipped with sonic anemometers (uSonic-983 Basic, Metek Gmbh, Hamburg, DE) installed at five different heights: $1.5 \mathrm{~m}(0.23 \mathrm{H})$, $4.0 \mathrm{~m}(0.62 \mathrm{H}), 6.0 \mathrm{~m}(0.92 \mathrm{H}), 8.5 \mathrm{~m}(1.31 \mathrm{H})$ and $11.0 \mathrm{~m}$ $(1.69 H)$ above ground level (a.g.l.). The two masts denoted as $\mathrm{M}_{1}$ and $\mathrm{M}_{2}$ in Fig. 2a-b were located in two anti-diametric locations from the tree. The positions were chosen in order to allow the simultaneous monitoring of the wind conditions in both the windward $\left(\mathrm{M}_{1}\right)$ and the leeward $\left(\mathrm{M}_{2}\right)$ directions when the wind direction was $290^{\circ}$. The sonic anemometers were installed on booms pointing towards the direction of $200^{\circ}$ relative to north on both masts. To get a higher coverage of the complex wind field in the tree wake, the $\mathrm{M}_{2}$ mast was instrumented with five additional sonic anemometers on opposing booms pointing towards $20^{\circ}$ relative to north. Based on the length of the booms, an array of 10 sonic anemometers was formed in the $\mathrm{M}_{2}$ mast, with a width of $3.6 \mathrm{~m}(0.55 \mathrm{H})$ and a height of $10 \mathrm{~m}(1.53 \mathrm{H})$. A flow distortion correction algorithm was applied to all the sonic anemometer highfrequency data $(20 \mathrm{~Hz})$ following the method described in Peña et al. (2019).

\section{Data analysis}

\subsection{Data selection and post-processing}

The field test using the scanning wind lidars was performed over a period of 1 month (October 2017), during which the wind direction was not suitable for our analysis the majority of the time. Here, we focus on a $3 \mathrm{~h}$ period (13:3016:30 UTC+1, 25 October 2017), during which the wind originated from the direction $270-310^{\circ}$. In this sector, the streamwise wind component $u$ is approximately aligned to the $x$ axis of the coordinate system, and the wake of the tree is expected to be within the scanning plane. The ambient mean wind speed varied between $7-15 \mathrm{~m} \mathrm{~s}^{-1}$ at all heights, except at the location of the lower sonic anemometer $(1.5 \mathrm{~m})$, which reported relatively lower wind speeds (Fig. A1). In order to assess the stationarity of the free flow, we define the timescale $\tau_{H}=u_{\star} / H$, where $u_{\star}=\left(\left\langle u^{\prime} w^{\prime}\right\rangle^{2}+\left\langle v^{\prime} w^{\prime}\right\rangle^{2}\right)^{1 / 4}$ is calculated from the $4 \mathrm{~m}$ sonic anemometer at the $\mathrm{M}_{1}$ mast, and $H$ is the tree height. Using the mean of the friction velocity $\left(0.4 \mathrm{~m} \mathrm{~s}^{-1}\right), \tau_{H}=16.25 \mathrm{~s}$. Over this timescale, a linear fit of the wind speed versus time showed a slope of less than $0.001 \mathrm{~m} \mathrm{~s}^{-1}$ per $\tau_{H}$, and the time series of the free flow is, therefore, considered to be stationary.

The local atmospheric conditions were characterized by neutral stability as the height normalized by the Obukhov length $L$ values, the so-called stability parameter, was found to be within the range $0<|z / L|<0.01$. The Obukhov length
$L$ was derived using the 10 min statistics based on the measurements of the windward sonic anemometer at $4 \mathrm{~m}$ through the expression

$L=-\frac{T_{o}}{\kappa g} \frac{u_{\star}^{3}}{Q_{o}}$,

where $T_{o}$ is the temperature at a height $z, \kappa$ is the von Karman constant, $u_{\star}$ is the friction velocity defined by $u_{\star}=$ $\left(\left\langle u^{\prime} w^{\prime}\right\rangle^{2}+\left\langle v^{\prime} w^{\prime}\right\rangle^{2}\right)^{1 / 4}, Q_{o}=\left\langle\theta^{\prime} w^{\prime}\right\rangle$ is the surface virtual temperature flux (here we use the sound virtual temperature measured by the sonic anemometer), and $g$ is the gravitational acceleration (Wyngaard, 2010).

The sonic anemometer measurements at $4 \mathrm{~m}$ on the $\mathrm{M}_{1}$ meteorological mast, which approximately corresponds to the height of the centre of the crown, were used as a reference of the horizontal wind speed and direction (Fig. 1a). Subsequently, the lidar data of each iteration of the scanning pattern were grouped according to their corresponding $26 \mathrm{~s}$ mean wind direction of the period when they were acquired. First- and second-order moments of the wind vector components on the lee side of the tree were estimated using the ensemble of the normalized data acquired by the individual scanning pattern iterations when the upwind direction was between $282-287^{\circ}$ (Fig. A2a). This wind direction sector was selected since it was the one with the most frequent occurrences (101 scanning pattern iterations). The wind speed during these occasions varied between $6.5-10.5 \mathrm{~m} \mathrm{~s}^{-1}$, with a mean of $8.05 \pm 0.80 \mathrm{~m} \mathrm{~s}^{-1}$ (Fig. A2b). The calculation of the wind statistics, and especially of the second-order moments, may still yield theoretically satisfactory results with relatively low systematic and random errors, even using few measurements, given that certain criteria are fulfilled. According to the work of Lenschow et al. (1994), these criteria are based on the high sampling frequency and the relation between the disjunct sampling time (here defined as the time between the scanning pattern iterations) and the time integral scale of the fluctuating quantity. We elaborate more on this issue in Sect. 5. Prior to the estimation of the wind statistics, two post-processing steps were performed.

First, a filter was applied to the wind lidar data. The filtering was based on the calculation of the inner and outer fence of the distribution of $w$ in each grid cell. Those wind vector estimations with a vertical component outside the two fences in each grid cell were treated as outliers and were not included in the analysis. Afterwards the wind speed measurements of each iteration were normalized by the corresponding $26 \mathrm{~s}$ mean wind speed $\left(u_{\mathrm{ref}}\right)$, acquired at $4 \mathrm{~m}$ at the upwind mast. The normalized quantities are indicated with the ${ }^{\wedge}$ symbol and presented using the Reynolds decomposition, where the mean and turbulent fluctuations are denoted by the \langle\rangle and' symbols, respectively. 


\section{Results}

\subsection{Vertical profiles}

In Fig. 3a-f, we show the vertical mean and variance of the longitudinal wind speed and the turbulent momentum transport (flux) profiles measured by the wind lidars (blue lines) and the sonic anemometers (red and orange filled circles for $\hat{y}=0$ and $\hat{y}=0.5$, respectively) located approximately $1.5 \mathrm{~m}$ downwind of the scanning plane (Fig. $3 \mathrm{a}$ and e). It is observed that the vertical profiles of the mean streamwise component measured by the lidars are consistent with the sonic anemometers, regardless of the vertical and spanwise distance. The difference between the individual first-order moment estimations of the two instruments varies between $-2.0 \%$ and $8.0 \%$, depending on the location. The smallest differences, lower than $2 \%$, are found at the lowest (i.e. $z=$ $1.5 \mathrm{~m}$ ) and highest (i.e. $z \geq 8.5 \mathrm{~m}$ ) heights. In the wake the differences are increased to $3.5 \%-8.3 \%$. Overall, a mean absolute difference of $3 \%$ is found between the two measuring instruments. Regarding the estimation of the secondorder moments, the vertical trends of variances and covariances measured by the sonic anemometers are also captured by the wind lidars (see Fig. 3b-d and g-i). The relative error in the longitudinal variance varies between $-6 \%$ and $-58 \%$. The maximum relative error is found in the sonic anemometer at the centre of the wake (sonic anemometer at $4 \mathrm{~m}$, south boom at $\mathrm{M}_{2}$ ), where the turbulence is very low. The observed underestimation of $\left\langle\hat{u}^{\prime} \hat{u}^{\prime}\right\rangle$ is attributed to the probe length of the wind lidar, which operates as a low-pass filter which attenuates the high-frequency fluctuations in the wind (Angelou et al., 2012b). Regarding the estimation of the momentum fluxes, we find overall relative error values that are up to $128 \%$ above the tree, but the error in the wake is limited to $20 \%$. This does not include the measurements of the vertical momentum fluxes at the lower height $(1.5 \mathrm{~m})$, which, due to the geometry of the experimental set-up, are found to be very sensitive to random noise. Furthermore, we have not included the vertical momentum flux measurement at $4 \mathrm{~m}$ at the north boom of the $\mathrm{M}_{2}$ mast since the correlation between the longitudinal and vertical component was found to be equal to $0 \mathrm{~m}^{2} \mathrm{~s}^{-2}$, leading to an unspecified relative error. The uncertainty in the first- and second-order statistics is estimated by splitting the ensemble in four equally sized subsets and subsequently calculating the ratio of the standard deviation of each moment with the square root of $n-1(n=4)$. The values are presented in Fig. 3 with a blue shaded area and error bars for the case of the scanning wind lidar and sonic anemometer measurements, respectively. An increasing measurement uncertainty with decreasing distance to the ground is observed for the vertical momentum in the height range of $0<\hat{z}<0.5$ (Fig. 3d and i), which can be explained by the low elevation angle of the lidars' line of sight. A low elevation angle makes the measurement of the horizontal velocity component relatively more accurate, whereas it deteriorates the accuracy of the vertical velocity component.

\subsection{Strong fluxes co-located with sharp gradients}

The lidar measurements reveal the statistics of the threedimensional wind vector in all the measurement points of the scanning plane (Fig. 2b). In this near-wake region of the tree, the shape of the deficit closely resembles the shape of the crown (see dashed line in Fig. 4a). The asymmetry of the deficit in the wake can be explained by heterogeneities in the tree's plant area density. At the height of the reference upwind speed $(\hat{z}=4.0 / 6.5=0.6)$, the minimum normalized wind speed observed in the wake is measured to be $27 \%$ of the upwind speed. This is more than what was observed for the summer period, where the minimum was closer to $10 \%$ (Dellwik et al., 2019), indicating that the tree at the time of the experiment in late October was in the abscission phase and that a significant number of leaves had been lost.

The edges of the wake are characterized by an increase in the streamwise variance $\left\langle\hat{u}^{\prime} \hat{u}^{\prime}\right\rangle$. This increase reveals a thin interface layer of high turbulence, with a width between 1$2 \mathrm{~m}(0.15-0.3 H)$, extending along the periphery of the tree's crown. This layer corresponds to the area where momentum transfer between the free wind and the centre of the wake takes place, and it is a typical feature of wakes generated by porous bodies (Huang et al., 1995; Bai et al., 2012). This area is characterized by strong wind speed gradients (Fig. 4b-c) that are co-located with strong turbulence that transports momentum towards the wake centre (Fig. $4 \mathrm{e}-\mathrm{f}$ ). The gradients were estimated by first calculating the forward difference in the mean longitudinal wind speed between neighbouring grid cells in the $y$ and $z$ direction and subsequently by finding the corresponding value in the coordinates of each cell using linear interpolation. The horizontal transport of streamwise momentum $\left\langle\hat{u}^{\prime} \hat{v}^{\prime}\right\rangle$ (Fig. 4e) has alternating signs on the left and right sides of the tree, indicating the inwards transport, and it is approximately half of the vertical transport of streamwise momentum $\left\langle\hat{u}^{\prime} \hat{w}^{\prime}\right\rangle$ measured above the tree (Fig. 4f).

\subsection{Test of the eddy-viscosity hypothesis}

The turbulent atmosphere contains motions at a large range of scales, and all predictions of its behaviour rely on simplifying models on how the smaller scales affect the momentum and scalar transport (Launder and Spalding, 1972). The most commonly used simplification for small-scale atmospheric transport is based on the eddy-viscosity hypothesis, which expresses the relation between the momentum fluxes and the local mean gradient (Boussinesq, 1877; Pope, 2000). According to the eddy-viscosity hypothesis the deviatoric part of the Reynolds stress tensor is related to the mean strain rate as

$\left\langle u_{i}^{\prime} u_{j}^{\prime}\right\rangle-\frac{1}{3}\left\langle u_{k}^{\prime} u_{k}^{\prime}\right\rangle \delta_{i j}=-v_{T}\left(\frac{\partial\left\langle u_{i}\right\rangle}{\partial x_{j}}+\frac{\partial\left\langle u_{j}\right\rangle}{\partial x_{i}}\right)$, 


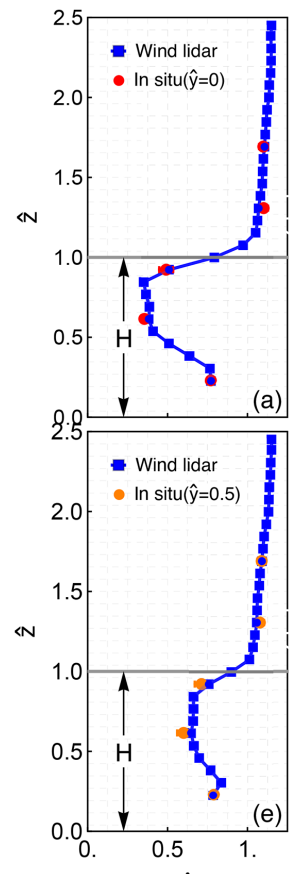

$\langle\hat{u}\rangle$
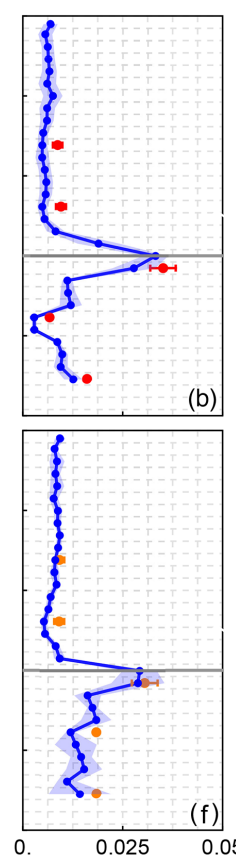

$\left\langle\hat{u}^{\prime} \cdot \hat{u}^{\prime}\right\rangle$
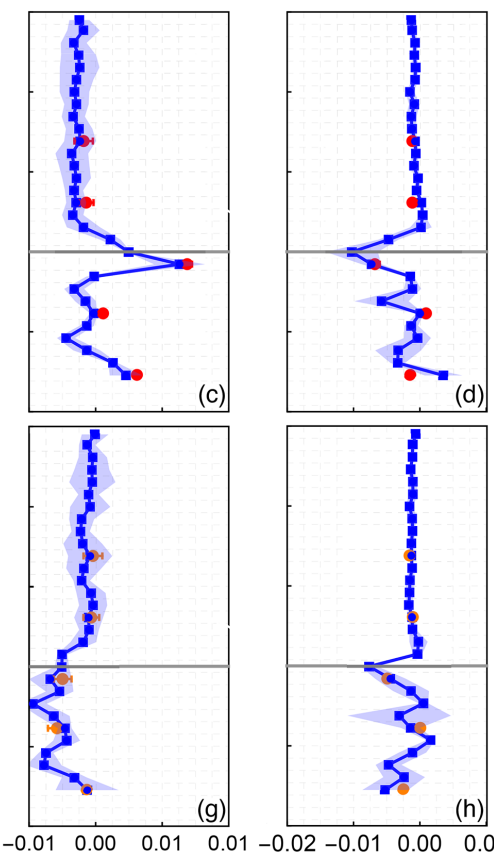

$\left\langle\hat{u}^{\prime} \cdot \hat{v}^{\prime}\right\rangle$

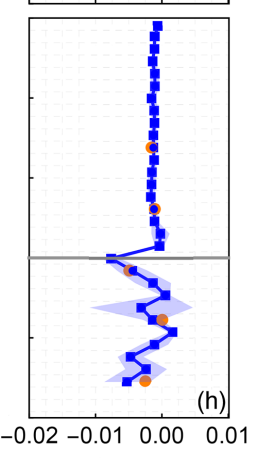

$\left\langle\hat{u}^{\prime} \cdot \hat{w}^{\prime}\right\rangle$

Figure 3. The vertical profile of the normalized mean streamwise wind speed $\langle\hat{u}\rangle$ (a, e), the longitudinal variance $\left\langle\hat{u}^{\prime} \hat{u}^{\prime}\right\rangle(\mathbf{b}, \mathbf{f})$, and the horizontal $\left\langle\hat{u}^{\prime} \hat{v}^{\prime}\right\rangle(\mathbf{c}, \mathbf{g})$ and vertical $\left\langle\hat{u}^{\prime} \hat{w}^{\prime}\right\rangle(\mathbf{d}, \mathbf{h})$ momentum fluxes, measured by the short-range WindScanner (blue) and downwind sonic anemometers in the centre of the wake at $\hat{y}=0(\mathbf{a}-\mathbf{d})$ and at $\hat{y}=0.5(\mathbf{e}-\mathbf{h})$. The blue area corresponds to the estimated values of the statistical uncertainty in each quantity (see more in the "Methods" section). The dashed horizontal line in (b) and (d)-(f) corresponds to the tree height.

where $v_{T}$ is the eddy diffusivity, which is a property of the flow, and the term $\frac{\partial\left\langle u_{i}\right\rangle}{\partial x_{j}}+\frac{\partial\left\langle u_{j}\right\rangle}{\partial x_{i}}$ represents the mean strain rate.

Although it is widely used in atmospheric modelling (e.g. Kaimal and Finnigan, 1994), the general applicability of the eddy-viscosity hypothesis is contested on theoretical grounds (Pope, 2000). Further, Schmitt (2007) claimed that it is almost never valid based on results from highly advanced numerical simulations around obstacles and in shear flows. A different argument against the validity of the eddy-viscosity hypothesis concerns its insufficiency for predicting the atmospheric transport of scalars and momentum since the local gradient and eddy viscosity only determine a minor part of the total turbulent transport. This argument has been used to explain observed counter-gradient fluxes inside dense forest canopies (Denmead and Bradley, 1985) by underlining that the main transport mechanism for scalars and momentum instead is the large-scale eddies (Raupach et al., 1996; Finnigan, 2000; Brunet, 2020). In this case, the atmospheric transport would not be successfully captured by an eddy-viscosity parameterization. In sparse canopies, characterized by threedimensional complexity, the validity of the eddy-viscosity hypothesis is also disputed (Finnigan et al., 2015). In this study we focus on the transport mechanism of the longitudinal momentum. For this purpose we construct a momentum vector from the following two components:

$\left\langle u_{1}^{\prime} u_{i}^{\prime}\right\rangle=-v_{T} \frac{\partial\left\langle u_{1}\right\rangle}{\partial x_{i}}$,

where $i=2,3$. With the above equation we want to express the relation between the momentum flux and mean gradient. This expression originates from Eq. (2), when the along-wind gradients of the vertical components $\left(\frac{\partial\left\langle u_{2}\right\rangle}{\partial x_{1}}\right)$ and transverse components $\left(\frac{\partial\left\langle u_{3}\right\rangle}{\partial x_{1}}\right)$ are considered to be negligible. We base this assumption on the estimated values of the along-wind gradients $\left(\frac{\partial\left\langle\hat{u}_{2}\right\rangle}{\partial \hat{x}_{1}}\right.$ and $\left.\frac{\partial\left\langle\hat{u}_{3}\right\rangle}{\partial \hat{x}_{1}}\right)$ using the wind lidar and sonic anemometer measurements at the 10 locations where sonic anemometers were installed on the $\mathrm{M}_{2}$ mast. The values that we find are 1 order of magnitude lower than the values of the transverse gradient, and therefore, a significant bias should not be expected by disregarding the along-wind gradient.

In Fig. 4b-c, we can visually observe that the areas with high gradients are also characterized by strong momentum fluxes with an opposite sign, as Eq. (3) requires. We investigate this further by selecting grid points with high $\left\langle\hat{u}^{\prime} \hat{u}^{\prime}\right\rangle$ compared to the undisturbed flow (for more information regarding the grid selection we refer to Appendix B). We chose these grid cells because they represent the area where the mixing of momentum between the free and wake flow takes place. In these grid cells, the angle of the gradient vector 

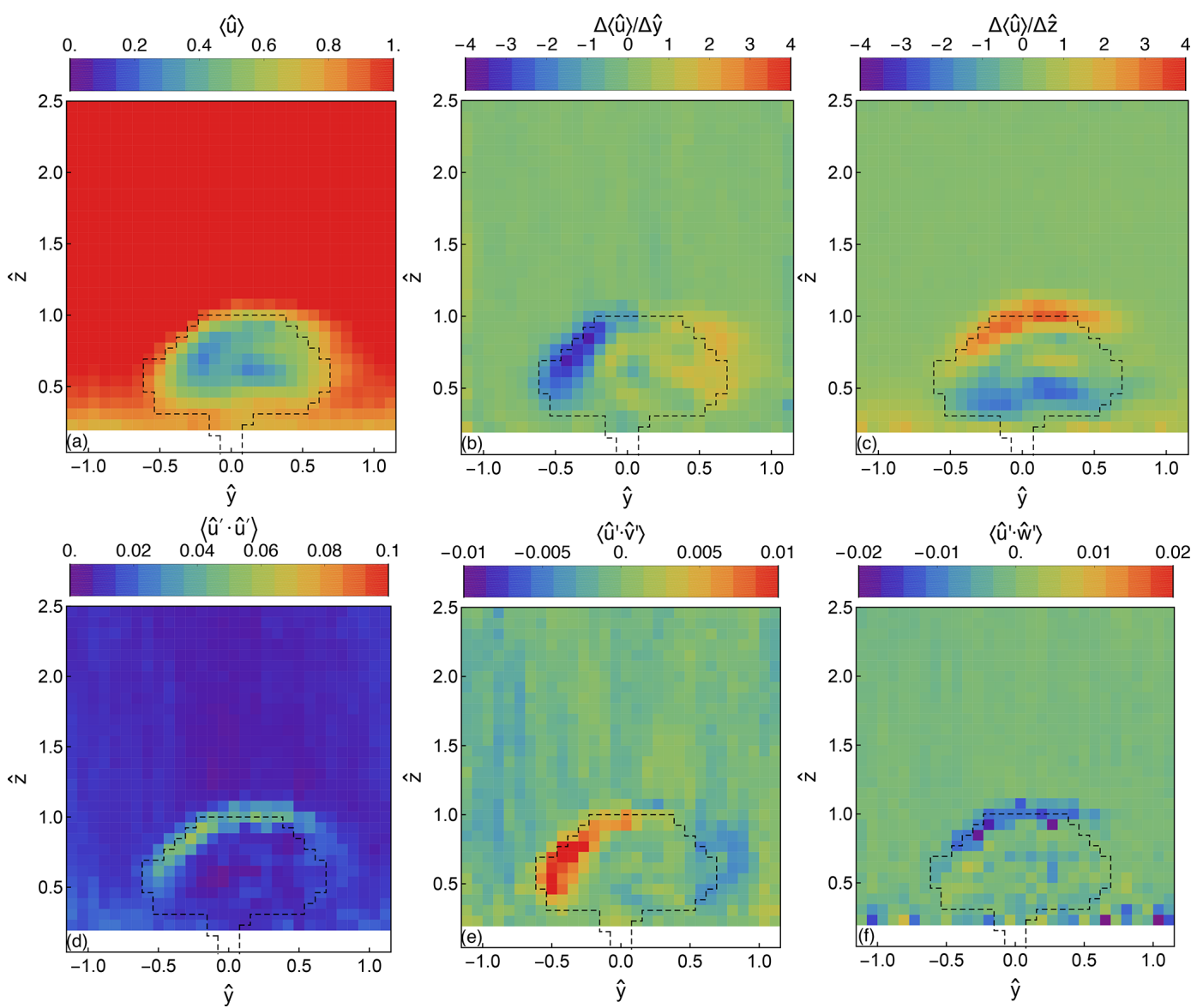

Figure 4. Normalized first and second moments of the wind on the lee side of the tree. (a) Mean streamwise component $\langle\hat{u}\rangle$, (b) spanwise $\Delta\langle\hat{u}\rangle / \Delta \hat{y}$ and (c) vertical $\Delta\langle\hat{u}\rangle / \Delta \hat{z}$ gradient of the mean streamwise component, (d) streamwise variance $\left\langle\hat{u}^{\prime} \hat{u}^{\prime}\right\rangle$, (e) horizontal $\left\langle\hat{u}^{\prime} \hat{v}^{\prime}\right\rangle$, and (f) vertical $\left\langle\hat{u}^{\prime} \hat{w}^{\prime}\right\rangle$ covariances of the longitudinal wind component. The dashed line in all figures represents the periphery of the tree.

(Fig. 5a) is radially pointing outwards from the centre of the crown, in the opposite direction of the vector of the momentum transport (Fig. 5b). In $90 \%$ of the selected grid cells the difference between the two vector directions is less than $30^{\circ}$, with a mean difference equal to $177^{\circ}$ and a standard deviation of $22^{\circ}$ (Fig. 5c). Using the same criterion as Schmitt (2007), we find that the observed relative direction of the two vectors supports a two-dimensional vectorial alignment, derived from the tensorial eddy-viscosity hypothesis.

\subsection{A small and near-constant turbulence mixing length}

A relatively simple parameterization of the eddy viscosity $v_{T}$ is constructed based on Prandtl's mixing-length hypothesis (Prandtl, 1925), which states that the eddy viscosity in an air volume is equal to the absolute local gradient of $u$ times the square of a turbulence mixing-length scale $l_{\mathrm{m}}$ :

$v_{T}=l_{\mathrm{m}}^{2}\left|\left(\frac{\partial\langle u\rangle}{\partial y}, \frac{\partial\langle u\rangle}{\partial z}\right)\right|$, where $\left|\left(\frac{\partial\langle u\rangle}{\partial y}, \frac{\partial\langle u\rangle}{\partial z}\right)\right|$ represents the Euclidean norm of the transverse gradient of $\langle u\rangle$. This length scale describes the characteristic distance over which an air parcel keeps its original properties, and it is an analogy to the mean free path in the statistical mechanics understanding of molecular viscosity. The concept can also be visualized as a characteristic size of the dominant turbulent eddy responsible for the mixing of the flow. By substituting Eq. (4) into Eq. (3), the mixing length can be expressed as a function of the length of the covariance and gradient vectors

$l_{\mathrm{m}}=\frac{\left(\left\langle u^{\prime} v^{\prime}\right\rangle^{2}+\left\langle u^{\prime} w^{\prime}\right\rangle^{2}\right)^{1 / 4}}{\left|\left(\frac{\partial\langle u\rangle}{\partial y}, \frac{\partial\langle u\rangle}{\partial z}\right)\right|}$,

which we use here to estimate a local length scale per grid cell using the normalized mean transverse gradient and momentum flux of $\langle u\rangle$. The results are presented in Fig. 6a and highlight the strong reduction in the mixing-length values between the free and wake flow.

We find that the horizontally averaged values of the normalized mixing length vary between $0.038-0.058$, which is 

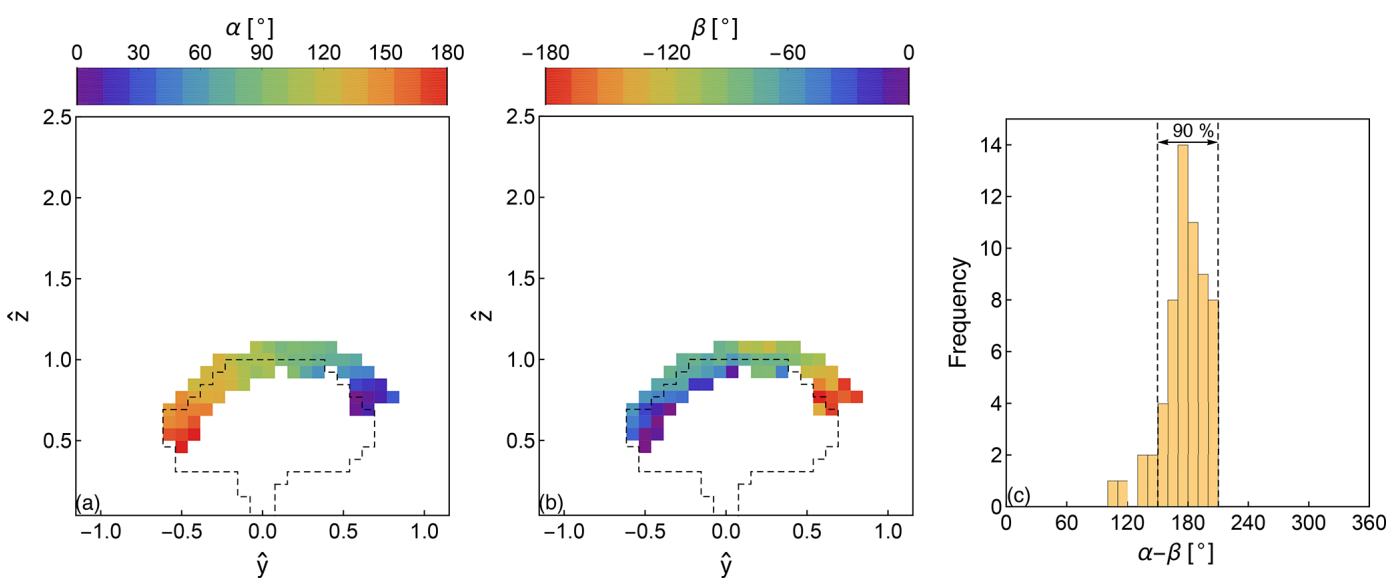

Figure 5. Direction of the mean gradient and momentum flux of the transverse wind speed vector. Direction of (a) the mean gradient $\frac{\partial\left\langle\hat{u}_{1}\right\rangle}{\partial \hat{x}_{i}}$ and (b) the covariance $\left\langle\hat{u}_{1}^{\prime} \hat{u}_{i}^{\prime}\right\rangle$ vectors. The dashed line in (a)-(b) represents the periphery of the tree. (c) Histogram of the direction difference between the two vectors. The dashed lines highlight the range where the two vectors have a difference less or equal to $\pi / 6$, which in this study is used as a validity index of Boussinesq's eddy-viscosity hypothesis.
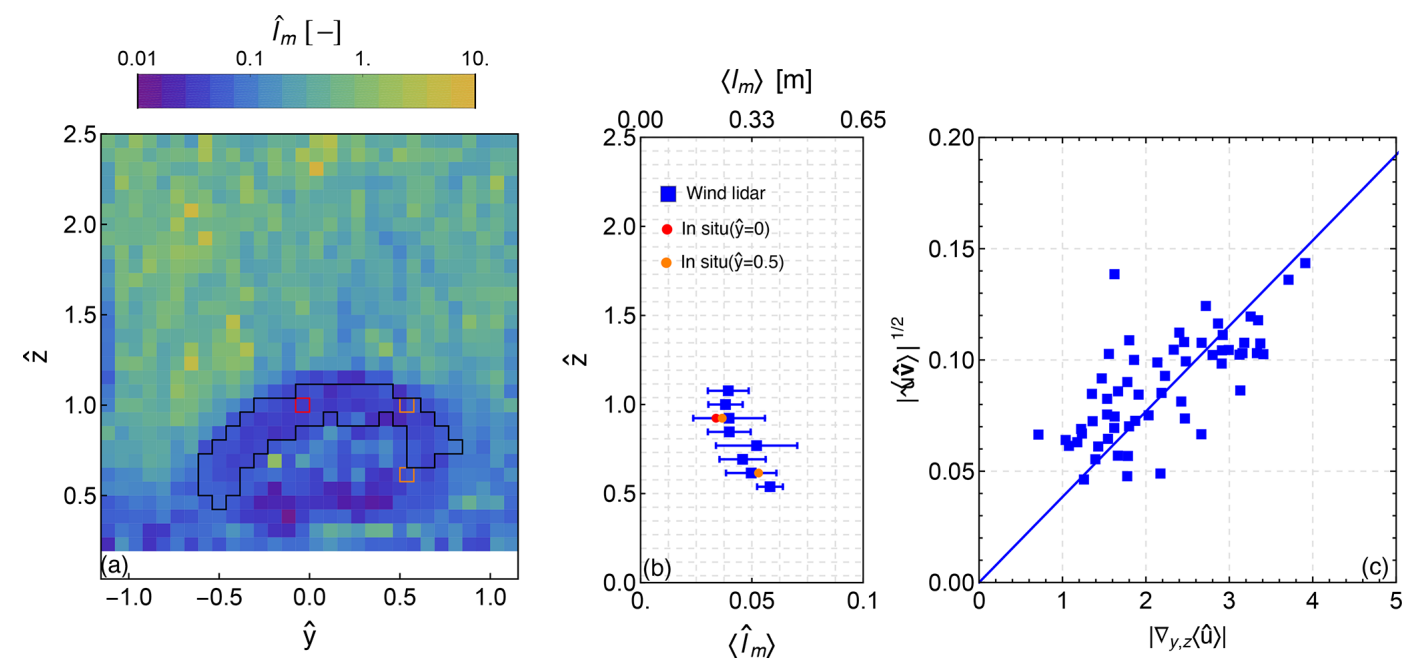

Figure 6. Turbulence mixing length. (a) Normalized mixing-length values $\left(\hat{l}_{\mathrm{m}}\right)$ along the scanning plane on the lee side of the oak tree presented in a logarithmic scale. The solid black line marks the wake region where high gradients are observed. The position of the colocated in situ sensors (sonic anemometer) in that region is highlighted with red $(\hat{y}=0)$ and orange $(\hat{y}=0.5)$. (b) Vertical profile of the horizontally averaged mixing length of the high gradient region of the wake (blue) and estimated mixing-length values based on the in situ wind measurements (in red and orange). (c) Scatter plot between the vectors of the mean gradient and of the momentum flux of the transverse wind. The solid blue line depicts a linear least squares fit forced through zero.

consistent with the estimation of the length scale using the sonic anemometer point measurements (presented in red and orange in Fig. 6b). The estimation of the mixing length using the sonic anemometer measurements was also based on Eq. (5) by combining the momentum flux measurements of the sonic anemometer with the co-located measurement of the gradient of the mean wind speed measurements from the scanning wind lidars. In those grid cells with high $\left\langle\hat{u}^{\prime} \hat{u}^{\prime}\right\rangle$ variance, the covariance vector estimations using the wind lidars have a maximum relative difference of $-6 \%$ in comparison with the observations from sonic anemometers.
The mixing length is observed to be near constant in the top part of the crown $(\hat{z}>0.8)$, with an increasing trend with decreasing height. In the lower heights we use measurements only from one side of the crown; therefore the observed trend could be biased since the crown is not homogeneously dense. Overall, we observe that the mixing length can be approximated by a constant value in this near-wake region based on the high correlation between the terms of Eq. (5) (Pearson correlation coefficient $r=0.7$; Fig. 6c). The average normalized mixing length is estimated to be equal to 0.038 , which corresponds to $0.25 \mathrm{~m}$. 
This value is 1 order of magnitude lower than the mixing lengths estimated in dense (Seginer et al., 1976; Poggi et al., 2004) and sparse (Pietri et al., 2009) artificial and simplified canopies. However, our result is in close agreement with the mixing-length values estimated in a wind tunnel study in the wake of a three-dimensional, fractal, tree-shaped structure (Bai et al., 2012). Yet, in that study, a clear height dependence of the mixing length was found, which was attributed to the vertical variations in the fractal complexity of the tree. Here, we do not observe a similarly strong trend (Fig. 6b). In the case of a mature, open-grown tree, leaves and branches of varying scales are inhomogeneously distributed in the crown volume. However, around the edges of the tree, the crown is characterized by similar density and size of the branches and twigs. This physical characteristic could explain the strong correlation between the length of the covariance and gradient vectors that supports the efficient description of the turbulence eddies in the wake edges using the mixing-length hypothesis. Hence, the effect of real open-grown trees on the turbulence transport at a given downwind distance can be represented in a simple way by approximating the mixing length with a constant value.

\section{Discussion and conclusion}

In this study we present spatially distributed measurements of the wind vector in the near-wake region of a solitary, mature oak tree. The measurements were acquired using a scanning remote sensing system that consisted of three synchronized continuous-wave wind lidars. The synchronous scanning, the high sampling frequency and the short probe volumes, relative to the wind flow characteristics, enabled the measurements of the first- and second-order moments of the flow, which depict the momentum fluxes between the free and wake flow.

From the $3 \mathrm{~h}$ long period examined in this study only 101 scanning pattern iterations were finally selected in the analysis due to the wind direction requirement that was chosen. The period of sampling in each grid cell $(26 s)$ is at least 5 times larger than the time integral scale of the momentum fluxes in the wake of the tree (see Fig. C1). This, in combination with the rapid sampling frequency of the wind lidars used here, enables the theoretical estimation of the systematic and random error in the calculated momentum fluxes in the wake of the tree based on Eq. (56) (systematic error) and Eq. (59) (random error) in Lenschow et al. (1994). We find that theoretically the largest contribution to be expected is due to random errors, which are estimated to be approximately equal to $15 \%$. The relative difference between momentum fluxes estimated using the wind lidar and sonic anemometer measurements in the wake area in those locations where high variance is observed was smaller than $20 \%$, and this can explain the good agreement between the corresponding length scale estimations which are presented in Fig. 6. A larger data sample would help reduce the random error variance of both the estimations of the secondorder moments and of the corresponding momentum fluxes. The reduction in random errors, in combination with smaller probe lengths of the wind lidar, would enable the study of the relation between the momentum fluxes and the mean gradients even in the centre of the wake, where very small gradients are observed.

Using the selected dataset, we show that in the layer of high turbulence that separates the wake from the free flow, the momentum fluxes of the streamwise component can be adequately predicted by the transverse gradient of the mean flow. This is good news since it means that relatively simple flow models that rely on the eddy-viscosity principle can be used to realistically reproduce the effect of trees, similar to the one studied here, for applications in agriculture, erosion prevention, air pollution and pollen dispersion as well as modelling of atmospheric transport at different scales. Realistic predictions of the momentum fluxes using the Boussinesq hypothesis are probably achievable also in the case of other small-scale tree configurations, as well as sparse canopies, where the flow can be characterized by a superposition of multiple wakes behind each single tree.

The results presented in this study highlight the value of remote sensing systems based on three synchronously scanning wind lidars to probe complex flows since a very high spatial resolution of the heterogeneous flow field could be achieved. Conventional in situ sensors such as sonic anemometers would not be able to provide such spatial detail without distorting the flow. The new capability to directly measure the three-dimensional turbulent fluxes over large planes can also be used to explore and describe other atmospheric flows that are difficult to correctly scale in wind tunnels. Hence, the presented measurement technology enables new possibilities of exploring and improving our description of the complex earth-atmosphere interaction. 
Appendix A: Wind conditions
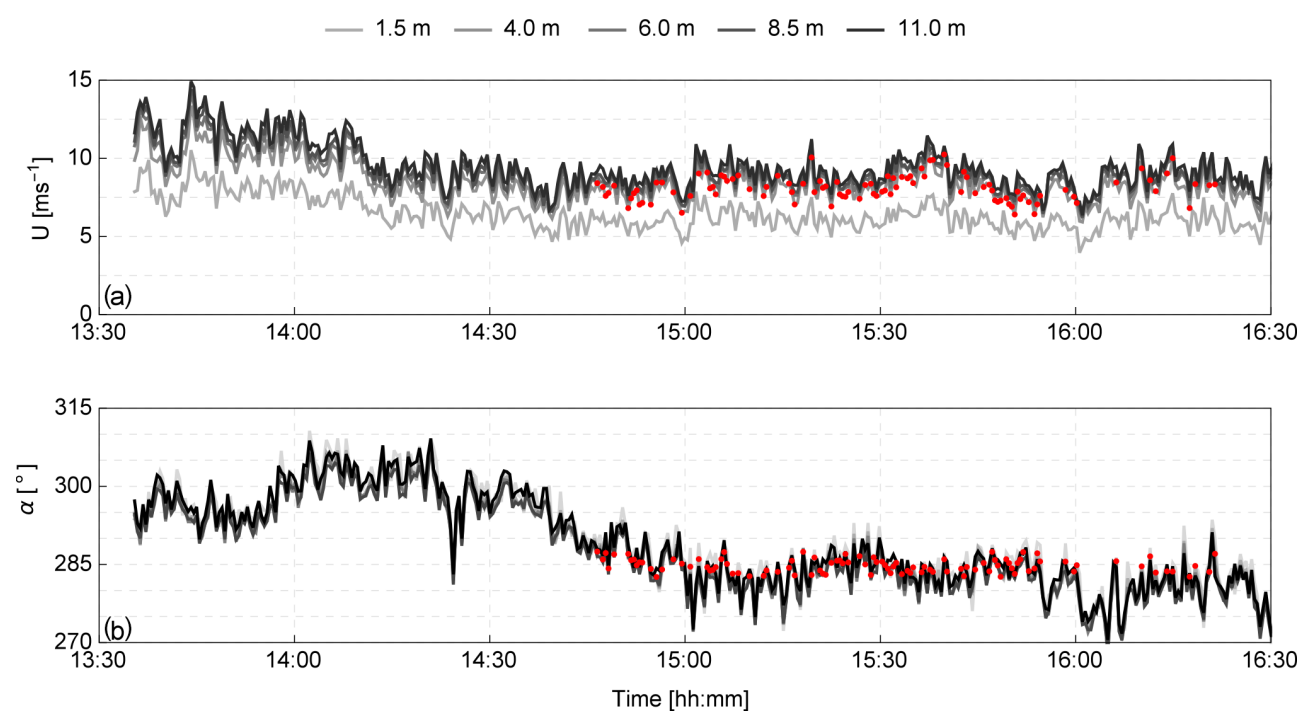

Figure A1. Time series of the $26 \mathrm{~s}$ mean wind speed (a) and direction (b) over a period of $3 \mathrm{~h}$ between 13:30-16:30 UTC+2 on 25 October 2017. The measurements were acquired by five sonic anemometers located on the $M_{1}$ mast 1.5, 4.0, 6.0, 8.5 and $11.0 \mathrm{~m}$ above ground level.
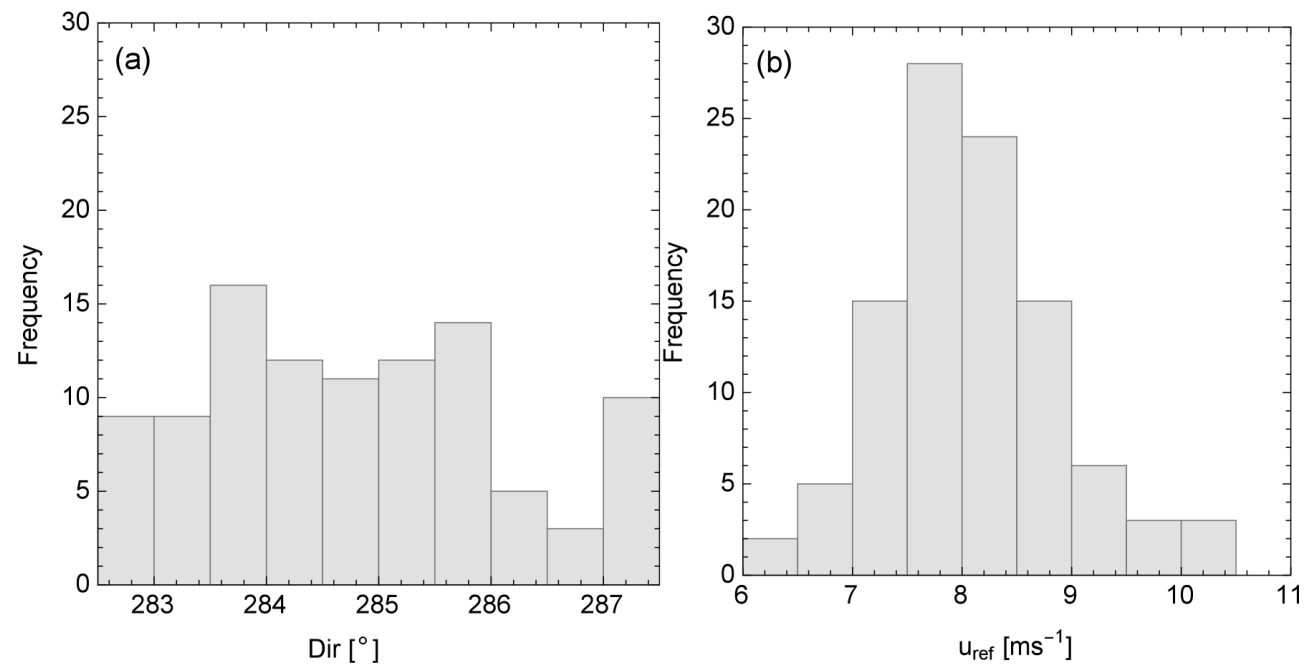

Figure A2. Histograms of the $26 \mathrm{~s}$ mean wind speed (a) and direction (b) over those periods when the mean wind direction was within the 282.5-287. $5^{\circ}$ sector. The measurements were acquired by the sonic anemometers located on the $\mathrm{M}_{1}$ mast, at $4.0 \mathrm{~m}$ above ground level. 
Appendix B: Grid cell selection for the validation of the Boussinesq hypothesis

The validity of Boussinesq's hypothesis was investigated in those grid cells characterized by high variance of the streamwise component $\left\langle\hat{u}^{\prime} \hat{u}^{\prime}\right\rangle$. The selection of those grid cells was performed by first averaging three vertical profiles of $\left\langle\hat{u}^{\prime} \hat{u}^{\prime}\right\rangle$ located at each of the two edges of the scanning plane in order to reconstruct the vertical variations in $\left\langle\hat{u}^{\prime} \hat{u}^{\prime}\right\rangle$ of the free flow (Fig. B1). Subsequently, all the measurements of the vertical plane were normalized by the reference $\left\langle\hat{u}^{\prime} \hat{u}^{\prime}\right\rangle_{\mathrm{f}}$ profile. Finally, those grid cells with normalized $\left\langle\hat{u}^{\prime} \hat{u}^{\prime}\right\rangle$ values higher than the statistical outer fence of the normalized $\left\langle\hat{u}^{\prime} \hat{u}^{\prime}\right\rangle$ distribution were chosen for the analysis.
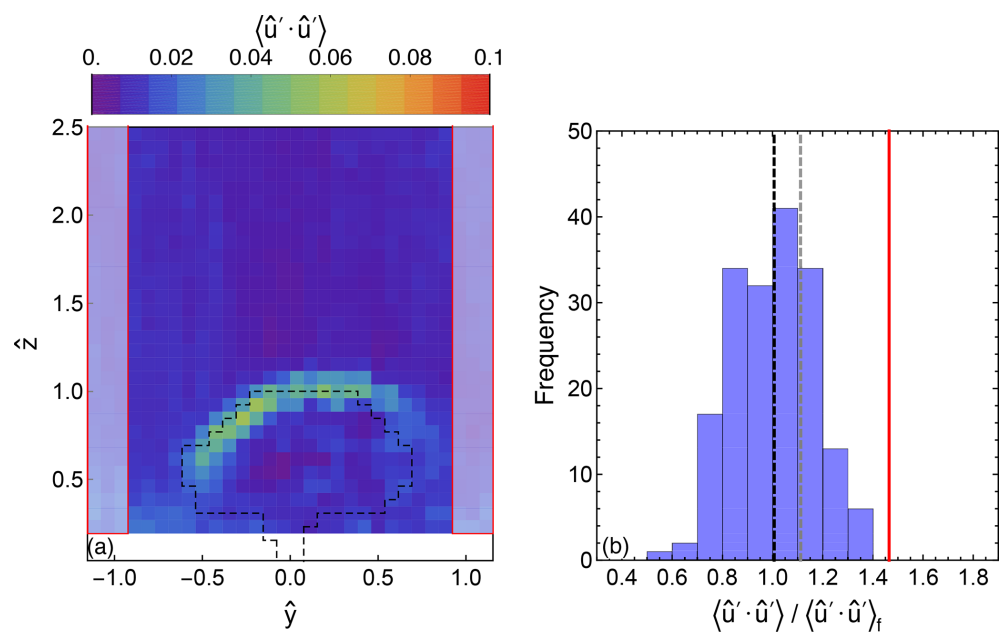

Figure B1. (a) Area used for the estimation of the reference variance of the free wind marked by the two red rectangles and (b) histogram of normalized variance $\left\langle\hat{u}^{\prime} \hat{u}^{\prime}\right\rangle /\left\langle\hat{u}^{\prime} \hat{u}^{\prime}\right\rangle_{\mathrm{f}}$ in the selected grid cells and the corresponding median (dashed black) and upper quantile (dashed grey) as well as the upper outer-fence (red) values; $\left\langle\hat{u}^{\prime} \hat{u}^{\prime}\right\rangle_{\mathrm{f}}$ denotes the height-dependent variance of the $u$ component of the free wind.

\section{Appendix C: Time integral scale of the momentum fluxes in the wake of the tree}

Figure $\mathrm{C} 1$ presents the estimated time integral scale of the vertical and horizontal momentum fluxes. For the calculation, the time series of the wind measurements from the sonic anemometers in the $\mathrm{M}_{2}$ meteorological mast were used. The time integral scale values at each height were estimated by integrating the autocorrelation function until the first time lag for which the autocorrelation function dropped to zero. We find that the time integral scale of the momentum fluxes in the wake of the tree (heights 4 and $6 \mathrm{~m}$ ) is between 2.22$4.53 \mathrm{~s}$ for $\left\langle u^{\prime} v^{\prime}\right\rangle$ and between $0.17-0.32 \mathrm{~s}$ for $\left\langle u^{\prime} w^{\prime}\right\rangle$. 

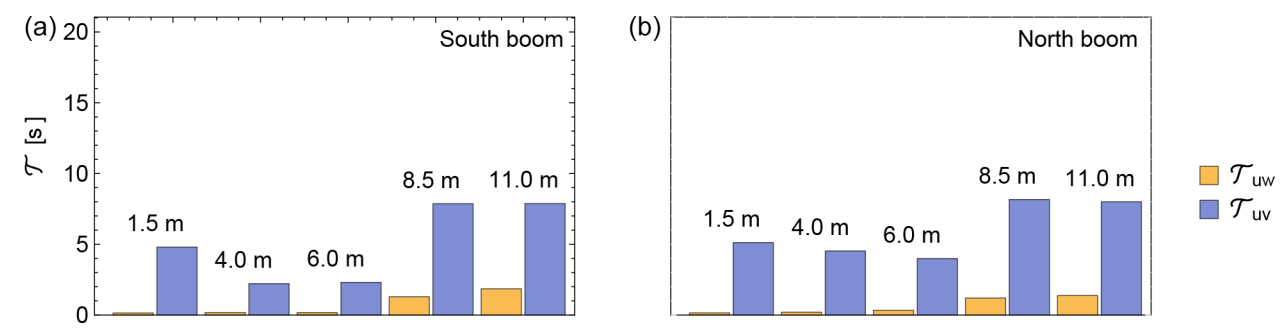

Figure C1. Time integral scale $\mathcal{T}$ of $\left\langle u^{\prime} v^{\prime}\right\rangle$ and $\left\langle u^{\prime} w^{\prime}\right\rangle$ estimated using the time series of the measurements acquired in each of the 10 sonic anemometers of the $\mathrm{M}_{2}$ meteorological mast, found on the south (a) and north (b) side of the mast.

Data availability. The data used in this study are available upon request.

Author contributions. ED and JM conceived the experiment. NA planned and conducted the experiment, post-processed and analysed the acquired data, and drafted the manuscript. ED and JM provided critical input and contributed to the interpretation of the results. All authors contributed to the writing of the final version of the manuscript.

Competing interests. The contact author has declared that neither they nor their co-authors have any competing interests.

Disclaimer. Publisher's note: Copernicus Publications remains neutral with regard to jurisdictional claims in published maps and institutional affiliations.

Acknowledgements. Claus Brian Munk Pedersen and Per Hansen, research technicians in the Wind Energy Department of DTU, are acknowledged for their valuable support during the realization of the experimental campaign. We thank the two anonymous reviewers, whose critical reading and constructive comments helped clarify and improve the paper.

Financial support. This research has been supported by the Danmarks Frie Forskningsfond (Independent Research Fund Denmark) (The Single Tree Experiment project (grant no. 6111-00121)).

Review statement. This paper was edited by Geraint Vaughan and reviewed by two anonymous referees.

\section{References}

Abari, C. F., Pedersen, A. T., and Mann, J.: An all-fiber imagereject homodyne coherent Doppler wind lidar, Opt. Express, 22, 25880-25894, https://doi.org/10.1364/OE.22.025880, 2014.

Angelou, N.: Wind-tree interaction: An experimental study on a solitary tree, PhD thesis, Technical University of Denmark, Denmark, https://doi.org/10.11581/dtu:00000078, 2020.

Angelou, N., Abari, F. F., Mann, J., Mikkelsen, T., and Sjöholm, M.: Challenges in noise removal from Doppler spectra acquired by a continuous-wave lidar, in: Proceedings of the 26th International Laser Radar Conference, Porto Heli, Greece, 25-29 June 2012, S5P-01, 2012a.

Angelou, N., Mann, J., Sjöholm, M., and Courtney, M.: Direct measurement of the spectral transfer function of a laser based anemometer, Rev. Sci. Instrum., 83, 033111, https://doi.org/10.1063/1.3697728, 2012b.

Bache, D. H.: Momentum transfer to plant canopies: Influence of structure and variable drag, Atmos. Environ., 20, 1369-1378, https://doi.org/10.1016/0004-6981(86)90007-7, 1986.

Bai, K., Meneveau, C., and Katz, J.: Near-Wake Turbulent Flow Structure and Mixing Length Downstream of a Fractal Tree, Boundary-Layer Meteorol., 143, 285-308, https://doi.org/10.1007/s10546-012-9700-2, 2012.

Boussinesq, J.: Essai sur la théorie des eaux courantes, Mémoires présentés par divers savants à l'Académie des Sciences XXIII, 1877.

Brunet, Y.: Turbulent Flow in Plant Canopies: Historical Perspective and Overview., Boundary-Layer Meteorol., 177, 315-364, https://doi.org/10.1007/s10546-020-00560-7, 2020.

Campi, P., Palumbo, A. D., and Mastrorilli, M.: Effects of tree windbreak on microclimate and wheat productivity in a Mediterranean environment, Eur. J. Agron., 30, 220-227, https://doi.org/10.1016/j.eja.2008.10.004, 2009.

Chen, L., Liu, C., Zhang, L., Zou, R., and Zhang, Z.: Variation in Tree Species Ability to Capture and Retain Airborne Fine Particulate Matter $\left(\mathrm{PM}_{2.5}\right)$, Sci. Rep., 7, 1-11, https://doi.org/10.1038/s41598-017-03360-1, 2017.

Cowan, I. R.: Mass, heat and momentum exchange between stands of plants and their atmospheric environment, Q. J. Roy. Meteor. Soc., 94, 523-544, https://doi.org/10.1002/qj.49709440208, 1968. 
de Langre, E.: Effects of Wind on Plants, Annu. Rev. Fluid Mech., 40, 141-168, https://doi.org/10.1146/annurev.fluid.40.111406.102135, 2008.

Dellwik, E., van der Laan, M. P., Angelou, N., Mann, J., and Sogachev, A.: Observed and modeled near-wake flow behind a solitary tree, Agr. Forest Meteorol., 265, 78-87, https://doi.org/10.1016/j.agrformet.2018.10.015, 2019.

Denmead, O. and Bradley, E. F.: Flux-Gradient Relationships in a Forest Canopy, in: The Forest-Atmosphere Interaction, edited by: Hutchison, B. A. and Hicks, B. B., 421-442, Springer, Dordrecht, https://doi.org/10.1007/978-94-009-5305-5_27, 1985.

Finnigan, J.: Turbulence in plant canopies, Annu. Rev. Fluid Mech., $32,519-571,2000$.

Finnigan, J., Harman, I., Ross, A., and Belcher, S.: First-order turbulence closure for modelling complex canopy flows, Q. J. Roy. Meteor. Soc., 141, 2907-2916, https://doi.org/10.1002/qj.2577, 2015.

Gosselin, F. P.: Mechanics of a plant in fluid flow, J. Exp. Bot., 70, 3533-3548, https://doi.org/10.1093/jxb/erz288, 2019.

Gromke, C. and Ruck, B.: Aerodynamic modelling of trees for small-scale wind tunnel studies, J. Forest, 81, 243-258, https://doi.org/10.1093/forestry/cpn027, 2008.

Gross, G.: A numerical study of the air flow within and around a single tree, Boundary-Layer Meteorol., 40, 311-327, https://doi.org/10.1007/BF00116099, 1987.

Hasenauer, H.: Dimensional relationships of open-grown trees in Austria, Forest Ecol. Manag., 96, 197-206, https://doi.org/10.1016/S0378-1127(97)00057-1, 1997.

Held, D. P. and Mann, J.: Comparison of methods to derive radial wind speed from a continuous-wave coherent lidar Doppler spectrum, Atmos. Meas. Tech., 11, 6339-6350, https://doi.org/10.5194/amt-11-6339-2018, 2018.

Henderson, S. W., Gatt, P., Rees, D., and Huffaker, R. M.: Laser Remote Sensing, 1st edn., edited by: Fujii, Takshi and Fukuchi, Tetsuo, CRC Press, ISBN 9780824742560, 2005.

Huang, Z., Kawall, J. G., Keffer, J. F., and Ferré, J. A.: On the entrainment process in plane turbulent wakes, Phys. Fluids, 7, 1130-1141, https://doi.org/10.1063/1.868554, 1995.

Jeanjean, A. P. R., Hinchliffe, G., McMullan, W. A., Monks, P. S., and Leigh, R. J.: A CFD study on the effectiveness of trees to disperse road traffic emissions at a city scale, Atmos. Environ., 120, 1-14, 2015.

Kaimal, J. and Finnigan, J.: Atmospheric Boundary Layer Flow, Their Structure and Measurement, Oxford University Press, https://doi.org/10.1093/oso/9780195062397.001.0001, 1994.

Kragh, J.: Road traffic noise attenuation by belts of trees, J. Sound Vib., 74, 235-241, 1981.

Landberg, L., Myllerup, L., Rathmann, O., Petersen, E. L., Jørgensen, B. H., Badger, J., and Mortensen, N. G.: Wind resource estimation - an overview, Wind Energy, 6, 261-271, 2003.

Launder, B. E. and Spalding, D. B.: Lectures in Mathematical Models of Turbulence, Academic Press Inc., London, England, ISBN $0124380506,1972$.

Lee, J. P., Lee, E. J., and Lee, S. J.: Shelter effect of a fir tree with different porosities, J. Mech. Sci. Technol., 28, 565-572, https://doi.org/10.1007/s12206-013-1123-6, 2014.

Lenschow, D. H., Mann, J., and Kristensen, L.: How Long Is Long Enough When Measuring Fluxes and Other Turbulence Statistics?, J. Atmos. Ocean.
Tech., 11, 661-673, https://doi.org/10.1175/15200426(1994)011<0661:HLILEW>2.0.CO;2, 1994.

Mann, J., Angelou, N., Arnqvist, J., Callies, D., Cantero, E., Arroyo, R. C., Courtney, M., Cuxart, J., Dellwik, E., Gottschall, J., et al.: Complex terrain experiments in the New European Wind Atlas, Philos. T. R. Soc. A, 375, 20160101 , https://doi.org/10.1098/rsta.2016.0101, 2017.

Mikkelsen, T., Sjöholm, M., Angelou, N., and Mann, J.: 3D WindScanner lidar measurements of wind and turbulence around wind turbines, buildings and bridges, IOP Conf. Ser. Mater. Sci. Eng., 276, 012004, https://doi.org/10.1088/1757-899x/276/1/012004, 2017.

Miller, D. R., Rosenberg, N. J., and Bagley, W. T.: Wind reduction by a highly permeable tree shelter-belt, Agr. Meteorol., 14, 321333, https://doi.org/10.1016/0002-1571(74)90027-2, 1974.

Miri, A., Dragovich, D., and Dong, Z.: Vegetation morphologic and aerodynamic characteristics reduce aeolian erosion, Sci. Rep., 7, $1-9,2017$.

Peña, A., Dellwik, E., and Mann, J.: A method to assess the accuracy of sonic anemometer measurements, Atmos. Meas. Tech. 12, 237-252, https://doi.org/10.5194/amt-12-237-2019, 2019.

Pietri, L., Petroff, A., Amielh, M., and Anselmet, F.: Turbulence characteristics within sparse and dense canopies, Environ. Fluid Mech., 9, 297-320, https://doi.org/10.1007/s10652-009-9131-x, 2009.

Poggi, D., Porporato, A., Ridolfi, L., Albertson, J., and Katul, G.: The Effect of Vegetation Density on Canopy SubLayer Turbulence, Boundary-Layer Meteorol., 111, 565-587, https://doi.org/10.1023/B:BOUN.0000016576.05621.73, 2004.

Pope, S. B.: Turbulent Flows, Cambridge University Press, https://doi.org/10.1017/CBO9780511840531, 2000.

Powers, J. G., Klemp, J. B., Skamarock, W. C., Davis, C. A., Dudhia, J., Gill, D. O., Coen, J. L., Gochis, D. J., Ahmadov, R., Peckham, S. E., et al.: The weather research and forecasting model: Overview, system efforts, and future directions, B. Am. Meteorol. Soc., 98, 1717-1737, https://doi.org/10.1175/BAMS-D-1500308.1, 2017.

Prandtl, L.: Bericht über Untersuchungen zur ausgebildeten Turbulenz, J. Appl. Math. Mech., 5, 136-139, 1925.

Raupach, M. R., Finnigan, J. J., and Brunet, Y.: Coherent eddies and turbulence in vegetation canopies: the mixing-layer analogy, Boundary-Layer Meteorol., 78, 351-382, 1996.

Schmitt, F. G.: About Boussinesq's turbulent viscosity hypothesis: historical remarks and a direct evaluation of its validity, C. R. Mécanique, 335, 617-627, https://doi.org/10.1016/j.crme.2007.08.004, 2007.

Seginer, I., Mulhearn, P. J., Bradley, E. F., and Finnigan, J. J.: Turbulent flow in a model plant canopy, Boundary-Layer Meteorol., 10, 423-53, 423-453, https://doi.org/10.1007/BF00225863, 1976.

Sjöholm, M., Angelou, N., Courtney, M., Dellwik, E., Mann, J., Mikkelsen, T., and Pedersen, A.: Synchronized agile beam scanning of coherent continuous-wave doppler lidars for highresolution wind field characterization, in: Proceedings of the 19th Coherent Laser Radar Conference, Okinawa, Japan, 18-21 June 2018, 19, ISBN 9781510870338, 2018.

Sogachev, A., Kelly, M., and Leclerc, M. Y.: Consistent twoequation closure modelling for atmospheric research: Buoyancy and vegetation implementations, Boundary-Layer Meteo- 
rol., 145, 307-327, https://doi.org/10.1007/s10546-012-9726-5, 2012.

Sonnenschein, C. M. and Horrigan, F. A.: Signal-to-Noise Relationships for Coaxial Systems that Heterodyne Backscatter from the Atmosphere, Appl. Optics, 10, 1600, https://doi.org/10.1364/ao.10.001600, 1971.
Telewski, F. W.: Wind-induced physiological and developmental responses in trees, in: Wind and Trees, edited by Coutts, M. P. and Grace, J., Cambridge University Press, 237-263, https://doi.org/10.1017/CBO9780511600425.015, 1995.

Wyngaard, J. C.: Turbulence in the Atmosphere, Cambridge University Press, https://doi.org/10.1017/CBO9780511840524, 2010. 